\title{
Development of a lemon cutting machine
}

\author{
A. Hrishikesh Tavanandi - S. Deepak • K. Venkateshmurthy • \\ K. S. M. S. Raghavarao
}

Revised: 22 November 2012 / Accepted: 30 November 2012 /Published online: 4 January 2013

(C) Association of Food Scientists \& Technologists (India) 2013

\begin{abstract}
Cutting of lemon and other similar fruits is conventionally done manually by sharp knife, which is labor intensive and often un-hygienic. In the present work, a device has been designed and developed for cutting of lemon hygienically into four pieces of similar shape based on stationery cutters and rotating centralizing/locating slit plate concept. Machine has a unique knife assembly consisting of two bird wing shaped knives, joined by welding perpendicularly to a vertical knife, so that the lemon can be cut into four pieces in a single sweep. Six numbers of rotating centralizing/locating slit plates are welded on to the side plates and the plates carry a groove on its inner face, to enable the wing shaped knife to complete the horizontal cut. The rotating slit plates, having centralizing angle of $90^{\circ}$, are rotated by an electric geared motor. The prototype machine has capacity of over 5,000 lemons/h with a power consumption of $0.11 \mathrm{~kW}$.
\end{abstract}

Keywords Lemon cutting machine - Design development . Prototype $\cdot$ Wing shaped knife $\cdot$ Centralizing disc

\section{Introduction}

Lemon is a yellow, spherical fruit grown on a small, vigorous, upright spreading, evergreen tree (C limon), which grows to a height of 3-7 m. Lemon is known to have originated in the eastern Himalayan region of India and adjoining areas (Cheema et al. 1954; Renther et al. 1967; Bose and Mitra 1990; Bose 1991), and cultivations in these regions dates back to $2400 \mathrm{BC}$ (Wolfgang 1970). Lemon is one of the major commercial crops, grown in many parts of

A. Hrishikesh Tavanandi $\cdot$ S. Deepak $\cdot$ K. Venkateshmurthy $(\bowtie) \cdot$ K. S. M. S. Raghavarao

Department of Food Engineering, CSIR- Central Food

Technological Research Institute, Mysore 570 020, India

e-mail: kvenkateshmurthy@yahoo.com the world. Its production worldwide is around 15 lakh tons. India is the largest producer of lemon with contribution of around 3 lakh tons (FAO-UN Estimate). Other major lemon growing countries are Algeria, Argentina, Australia, China, South America (Wolfgang 1970).

Although not edible in the same manner as most other citrus and deciduous fruits, lemon probably has a greater variety of culinary, beverage, industrial and medicinal uses than any other fruit (Breverman 1949). Lemons are used either as cut fruit or in juice form, based on the need and convenience. They are known to possess nutritive as well as medicinal values, mainly as rich source of vitamin $C$. Further, they contain other vitamins also such as vitamin $\mathrm{B}$, riboflavin and minerals like calcium, phosphorous, magnesium besides proteins and carbohydrates. Lemons are known to reduce risk of heart diseases, cancer and also work as antiseptic, astringent, digestive stimulant etc. (Milind 2008). An average lemon yields $0.015 \sim 0.020 \mathrm{~L}$ of juice when squeezed. Lemon juice is about 5-6\% (approximately $0.3 \mathrm{M}$ ) citric acid, which gives it a sour taste and a pH of 2-3 (Bose 1991).

Pickle is very popular in Asia and Latin America and is part of daily meal. The ease with which pickles can be prepared has rendered them very popular (Anonymous 1947). Pickles add zest and variety to meals as they please both the eye and the palate (Brown 1955). Lemon pickle is considered as one of the most liked and preferred one because of its taste and high shelf life (Pandey et al. 2011). Lemon pickle is prepared by putting sliced lemons into earthenware, enamel, or porcelain pan along with salt and spices which will be boiled slowly in vinegar for around half an hour and then stored in a large stone jar with regular stirring (Brown 1955). Indian lemon pickles are prepared in a totally different manner, that is, by cutting the lemon into four pieces and adding salt in required proportion for preservation. Blend of lemon and salt is kept for $3 \sim 4$ days for curing and garnished using oil and Indian spices such as, asafetida, red chilly powder, turmeric, fenugreek, mustard etc. (Chicoine and Joncas 1973). 
During recent years, the food manufacturer has witnessed several sections of the food industry to undergo a rapid expansion and come into prominence (Binsted 1939). Pickle industry is one such example. Today's consumers run the gamut - from those who want healthier choices to others who want unique flavors. This increased volume and diversity of products is causing food processing industries to design their lines based on shorter production runs with more changeovers. Meeting these demands requires operational flexibility. Industry must be able to easily replace raw materials according to demand and/or availability and quickly implement new operational procedures, keeping high sanitation in mind.

In pickle and beverage industries, cutting of lemon is a major step. Cutting of lemon and other similar fruits is conventionally done manually by a sharp knife which is tedious and unhygienic. To address these challenges, it is needed to implement automation (mechanization) to maintain product consistency and improve manufacturing flexibility and agility. Automation helps not only in time and product management but also in energy conservation, hygiene, resource management besides providing safety to labour. Development of a machine would enable to address these issues while enhancing uniformity in quality as well as quantity. Custom built machines were developed for different applications such as coconut opening, leaf area measurement, coconut trimming, betel nut de-husking, cassava cake pulverization, splitting and breaking of pistachio nuts and potato grading (Jarimopas et al. 2002a; b; 2006; 2009a; b; Jarimopas and Pramote 2007; Sanni et al. 2008; Bilim and Polat 2008; Ghanbarian et al. 2010). In order to facilitate the production of Indian traditional foods, extensive research has been carried out on design and development of equipment (Venkateshmurthy and co-workers 2002, 2003, 2008)

The objective of this research is to design and develop a continuous lemon cutting machine flexible enough to handle other similar citrus fruits depending on the requirement of the pickle industry. The machine will facilitate cutting of lemon hygienically into four pieces.

\section{Material and methods}

Design and operation

A preliminary prototype was designed. The engineering drawing of this continuous lemon cutting machine is shown in Fig. 1. It comprises of a geared motor (a) housed in the main frame (b). A square/rectangular tray (c) was provided on top of the equipment for holding the unsorted lemons. A gradient of $10 \sim 15^{\circ}$ was provided to the tray to facilitate feeding/rolling of the lemons into the chute (d). The outlet of the tray was connected to one end of the circular chute (d) which is fastened to the main frame (b). Other end of the chute was directed towards the stopper (e), which was provided for stopping the individual lemons at a predetermined radius of $0.1 \mathrm{~m}$ from the centre of the side plate so that the centralizing disc (f), welded to the rotating side plates $(\mathrm{g})$, can centralize (accommodating the variation in diameter of the lemons) and carry the lemons upwards. These centralized lemons are conveyed against the stationery knife assembly (h) of vertical knife and bird wing
Fig. 1 Drawings of continuous lemon cutting machine
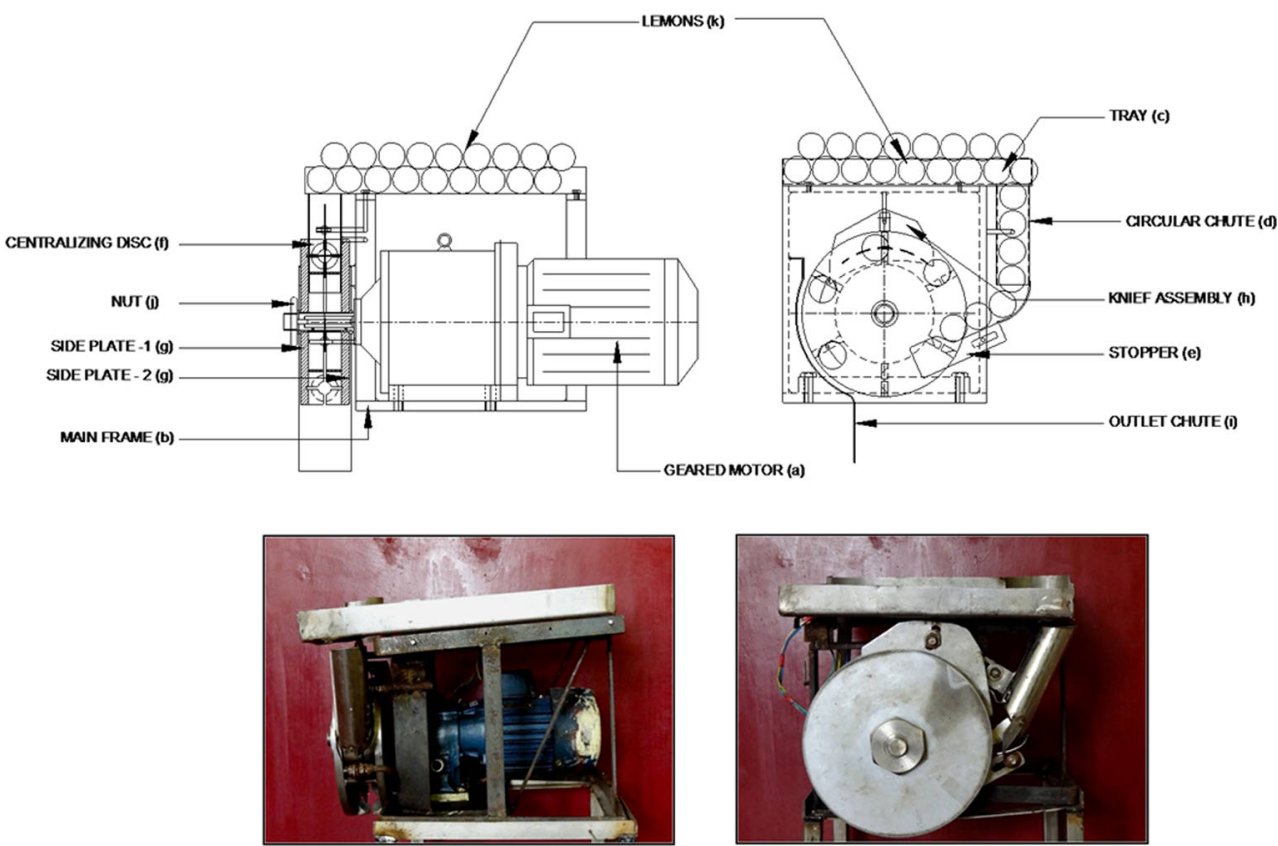

FRONT VIEW

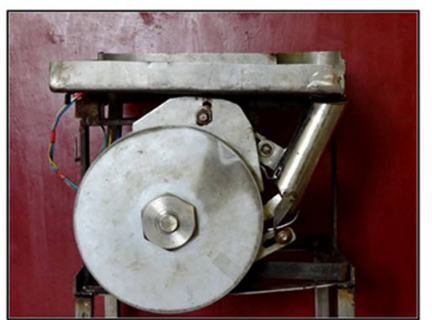

END VIEW 
shaped knives, almost simultaneously. The vertical knife, in first instance, cuts the lemon into two halves and the horizontal (wing shaped) knife, in turn, cuts these two into four pieces. The side plates are provided with groove on their inner face in order to enable the wing shaped knife to complete the horizontal cut. The material of construction of the side plates, centralizing discs, knife assembly, main frame, circular chute, locating stopper, tray and the cover are of stainless steel $(316 \mathrm{~L})$ for hygiene and aesthetic look.

Raw materials and capacity of processing

Lemons employed during the trials were of $0.040 \sim 0.046 \mathrm{~m}$ in diameter, having a mass ranging from $0.028 \mathrm{~kg}$ to $0.037 \mathrm{~kg}$ and were in yellow colour. The machine has been designed for the capacity in the range 1,200-5,040 lemons/ $\mathrm{h}$ for the given groove radius $(0.1 \mathrm{~m})$ within the limits of the number of centralizing discs (6 nos.) and rotational speed (10-14 RPM).

\section{Angular cutting velocity}

Fresh lemons of diameter ranging from $0.040 \mathrm{~m}$ to $0.046 \mathrm{~m}$ were purchased from local market. The linear velocity required to cut the lemons was experimentally determined by measuring the linear distance travelled by the knife to cut them completely and the time required to do so. The linear velocity thus obtained was translated to angular velocity $(\omega)$ of the centralizing disc against the stationary knife assembly (having vertical knife with arc radius $(\mathrm{R})$ of $0.085 \mathrm{~m}$ and wing shaped knife with arc radius of $0.1 \mathrm{~m}$ ) corresponding to the rated speed of 10 14 RPM. In order to ensure complete cutting of lemons continuously, the angular velocity $(\omega)$ of the centralizing disc was kept higher than the lowest linear velocity of conventional knife cutting.
Design of centralizing disc

Centralizing of the lemon is important for cutting of the lemon into four pieces of similar size and shape. To centrally locate the lemons (nearly spherical), a cone angle of $90^{\circ}$ (included angle) has been provided in the centralizing discs as shown in Fig. 2, which will locate the lemons, hold them firmly in the cone and also facilitate the release of cut lemon pieces. The number of sets of centralizing discs are varied from 2 to 6 and are mounted (welded) on the side plates. It may be noted that, centralizing discs are provided with radial slit and vertical gap of $0.005 \mathrm{~m}$ (as shown in Fig. 2) to allow free rotational movement of the vertical and horizontal (wing shaped) knives through them (discs).

\section{Determination of the knife angle and its positioning}

The knife assembly is unique as it is made of two bird wing shaped knives, joined by welding perpendicularly to a vertical knife, so that the lemon can be cut into four pieces of similar size and shape in a single sweep. The cutting edges of vertical and bird wing shaped knives have two angles namely, relief face angle and cutting angle as shown in Fig. 3. These angles are very important as they would decide the extent of oozing of the juice from the fruit during cutting, which is one of the prime requirements for pickle industry.

Positioning of vertical leading edge and horizontal wing shaped knife leading edge is very important as shown in Fig. 3 because it ensures complete cutting of lemons. Right positioning of vertical leading edge will provide sufficient time for the centralizing disc to accommodate the lemons in the cone during its rotation, whereas right positioning of horizontal wing shaped knife will facilitate complete cutting of lemons.
Fig. 2 Drawings of side plates and centralizing discs

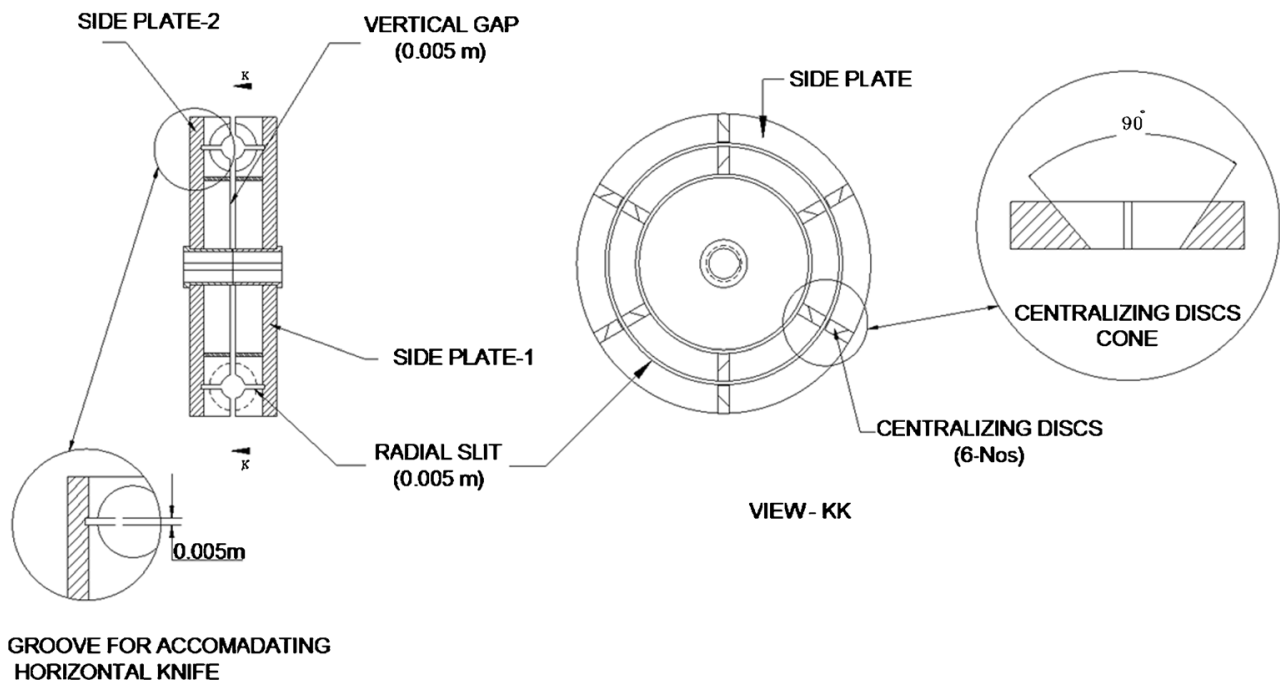


Fig. 3 Drawings of wing shaped cutter

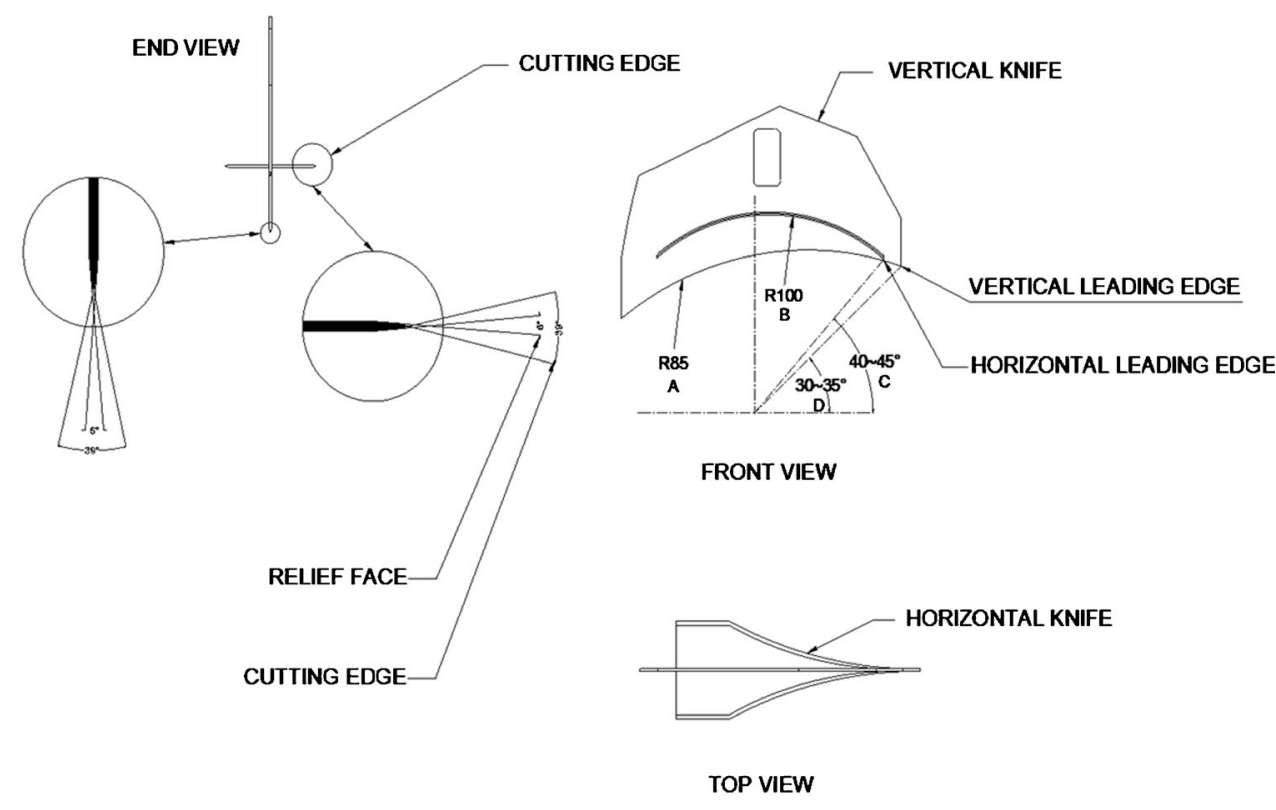

\section{A - VERTICAL CUTTER RADIUS \\ B- HORIZONTAL CUTTER RADIUS \\ C - ENTRY ANGLE OF HORIZONTAL CUTTER \\ D - ENTRY ANGLE OF VERTICAL CUTTER}

The photographic view of side plate and centralizing discs as well as knife assembly are as shown in the Fig. 4a and $b$, respectively.

Determination of shear force and power requirement for the machine

Power/Load requirement for the continuous lemon cutting machine was calculated in the following manner.

Individual lemons were subjected to shear between parallel knives of the textural analyzer (Model TA-HD $\mathrm{H}_{\mathrm{i}}$ Stable
Microsystems, Surrey, UK) at a cross head speed of $0.050 \mathrm{~ms}^{-1}$ up to $80 \%$ of their original height, in two directions namely, along and across the axis of lemons. The slope of minor peak and maximum force corresponding to minor as well as major peaks were determined using the software provided by the instrument manufacturer.

The values of shear stress for the lemon in both the axes were calculated using the following equation.

Shear stress(along and across the axis $)=$ Shear load/Area of cross section.
Fig. 4 (A1), side plate and centralizing disc, (A2), knife assembly
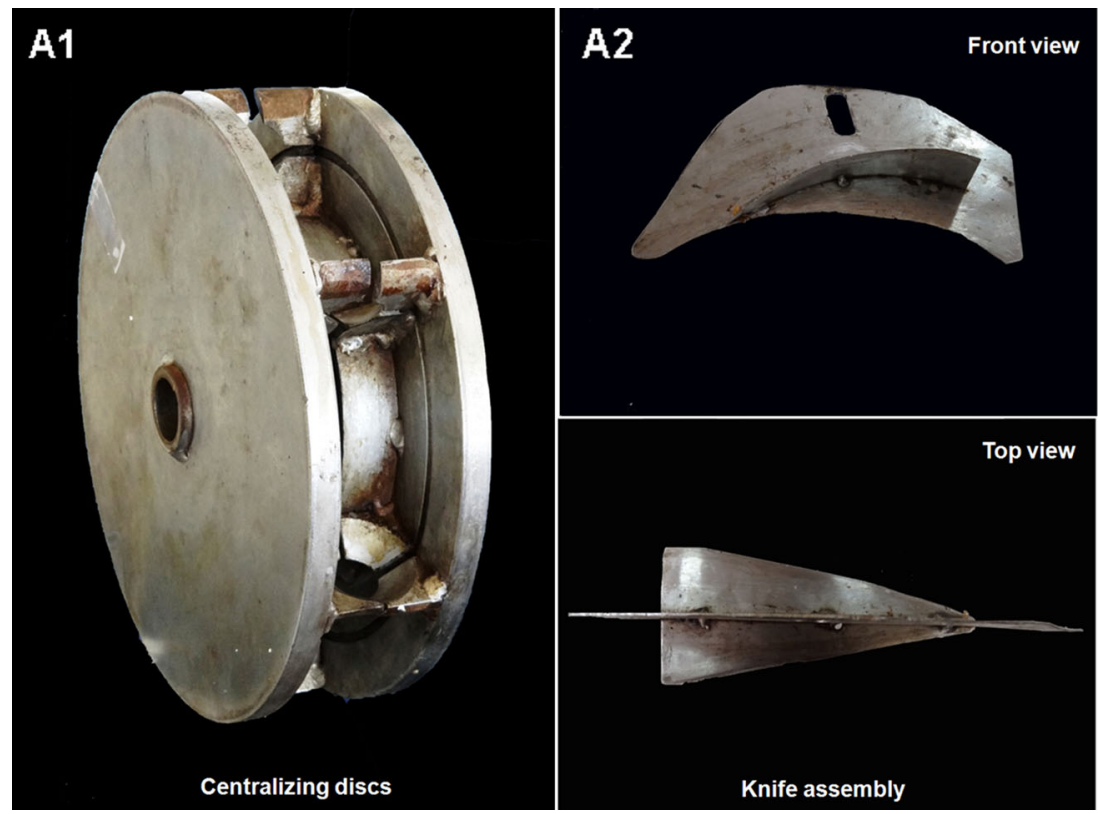
Table 1 Shear force and shear stress values for lemon

\begin{tabular}{llll}
\hline $\begin{array}{l}\text { Shear } \\
\text { force }(\mathrm{N})\end{array}$ & $\begin{array}{l}\text { Diameter of } \\
\text { lemon }\left(\mathrm{m} \times 10^{-3}\right)\end{array}$ & $\begin{array}{l}\text { Mass of lemon } \\
\left(\mathrm{N} \times 10^{-3}\right)\end{array}$ & $\begin{array}{l}\text { Shear stress } \\
\left(\mathrm{N} / \mathrm{m}^{2} \times 10^{3}\right)\end{array}$ \\
\hline $\begin{array}{l}\text { Across the axis } \\
325.0\end{array} \quad 39.8$ & & \\
322.0 & 45.1 & 275.56 & 205 \\
341.0 & 45.6 & 359.77 & 201 \\
Along the axis & 359.79 & 208 \\
433.0 & 43.7 & & \\
279.0 & 39.3 & 316.656 & 288 \\
415.0 & 41.0 & 286.78 & 230 \\
\hline
\end{tabular}

Cross head speed used in each case for determining shear force and shear stress values was $500 \times 10^{-3} \mathrm{~m} / \mathrm{min}$

Torque (T) required for the geared motor was calculated using the equation

$\mathrm{T}=\mathrm{F} \times \mathrm{r}$

where, $\mathrm{T}$ is in $\mathrm{N}-\mathrm{m}, \mathrm{F}$ is the maximum shear force to cut the lemon in $\mathrm{N}$ and $\mathrm{r}$ is the average radius of the vertical and horizontal cutter in $\mathrm{m}$.

Power $(\mathrm{P})$ of the prime mover/geared motor could be obtained by substituting the value the Torque in following equation.

$\mathrm{P}=2 \pi \mathrm{N}_{\mathrm{r}} \mathrm{T} / 4500$

where, $\mathrm{P}$ is in horsepower and $\mathrm{N}_{\mathrm{r}}$ is the rotational speed of geared motor in RPM

Capacity (C) of the machine was calculated from the following equation

$\mathrm{C}=\mathrm{n} \times \mathrm{N}_{\mathrm{r}} \times 60$

where, ' $\mathrm{C}$ ' is in lemons/hour, ' $\mathrm{n}$ ' is the number of centralizing discs.

After arriving at the most suitable design and process parameters, performance evaluation of the machine has been carried out.

\section{Results and discussion}

Angular cutting velocity

Conventional cutting of any fruit including lemon is by linear movement of knife into the fruit. During manual cutting of lemon, the rate (linear velocity of knife movement) of incision was found to be in the range of 0.042 to $0.060 \mathrm{~ms}^{-1}$. In order to maintain the required velocity of knife assembly, in other words, that of centralizing disc, the arc radius of the vertical knife is kept at $0.085 \mathrm{~m}$ to have an angular cutting velocity of 0.09 to $0.13 \mathrm{~ms}^{-1}$ over the rated speed of 10 to 14 RPM. A typical calculation of arriving at the angular cutting velocity is shown in the Appendix.

\section{Design of centralizing disc}

Centralizing of the lemon is important for cutting it into four pieces of uniform size and shape. To centrally locate the lemons (nearly spherical), a cone angle of $90^{\circ}$ (included angle) has been provided in the centralizing discs as shown in Fig. 2, which will hold the lemon in position during cutting. The lemons (similar spherical fruits) having a diameter ranging from $0.040 \mathrm{~m}$ to $0.046 \mathrm{~m}$ were centralized in the centralizing disc by feeding them continuously one by other with the help of the circular chute (Fig. 1). For the arc radius $(R)$ of the vertical knife $(0.085 \mathrm{~m}$, Appendix), the maximum number of centralizing discs that can be positioned on the side plates is six. Thus six centralizing discs were mounted (welded) on the side plates, which were rotated over the rated speed $(10 \sim 14 \mathrm{RPM})$ thereby deciding the rated capacity of the equipment $(3,600-5,040$ lemons/h). A vertical gap of $0.005 \mathrm{~m}$ was provided (as shown in Fig. 2) between the centralizing discs, welded to the side plates, accommodating the free passage of the vertical knife. Similarly, the radial slit of $0.005 \mathrm{~m}$ of the centralizing discs allows free rotational movement of the side plates with free passage of the wing shaped stationary knife, ensuring complete cutting of lemons.

The centralizing of lemons was achieved effectively at a cone angle of $90^{\circ}$ (included angle) of the centralizing discs. Other cone angles, either lower or higher than $90^{\circ}$, will result in lower stability of lemons in the centralizing discs.

Knife angle and its positioning

As already mentioned, knife assembly is unique as it is made up of two sub-knives, which are joined by welding perpendicular to a vertical knife, so that the lemon can be cut into four pieces of similar size and shape in a single sweep. The knife has two angles namely, relief face angle

Table 2 Effect of rotational speed on lemon juice ejection

\begin{tabular}{lllll}
\hline $\begin{array}{l}\text { Rotational } \\
\text { speed } \\
(\text { RPM })\end{array}$ & $\begin{array}{l}\text { Vol. of juice } \\
\text { oozed out } \\
\left(1 \times 10^{-3}\right)\end{array}$ & $\begin{array}{l}\text { Vol. of juice } \\
\text { oozed out } \\
\text { per lemon } \\
\left(1 \times 10^{-3}\right)\end{array}$ & $\begin{array}{l}\text { Theoretical } \\
\text { Capacity } \\
\text { (Nos./h) }\end{array}$ & $\begin{array}{l}\text { Experimental } \\
\text { Capacity } \\
\text { (Nos./h) }\end{array}$ \\
\hline 10 & 24.0 & 0.53 & 3600 & 3570 \\
11 & 23.5 & 0.52 & 3960 & 3920 \\
12 & 31 & 0.68 & 4320 & 4285 \\
13 & 25 & 0.55 & 4680 & 4645 \\
14 & 24.5 & 0.54 & 5040 & 5000 \\
\hline
\end{tabular}

Number of lemons used in each case for juice ejection was 45 and number of centralizing discs in each case was 6 


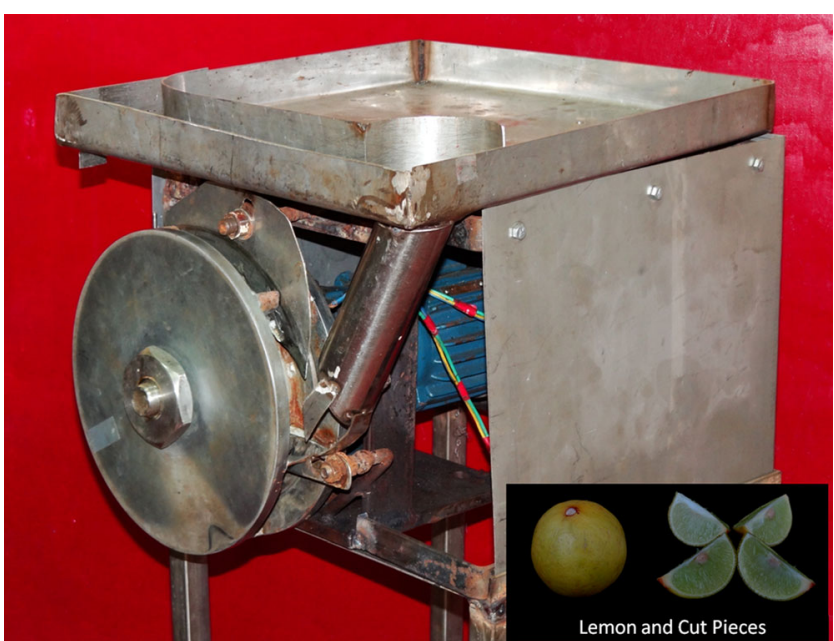

Fig. 5 Continuous lemon cutting machine

and cutting angle (as shown in Fig. 3). The relief face angle of $5 \sim 6^{\circ}$ and cutting angle of $38 \sim 39^{\circ}$ are provided in order to maintain a low juice ejection. During the performance trials, it was found that these angles have resulted in very low oozing of juice.

The leading edge of the vertical knife is kept at about $30 \sim 35^{\circ}$ (as shown in Fig. 3) to the horizontal reference axis having an arc length of $0.045 \sim 0.052 \mathrm{~m}$ which provided sufficient time for the centralizing disc to accommodate the lemons in the cone during its rotation. Leading edge of the horizontal wing shaped knife is positioned at about 40 $45^{\circ}$ to the horizontal reference axis having an arc length of about $0.070 \sim 0.079 \mathrm{~m}$ which allowed the lemon to get partially cut (vertically) and get the support of vertical knife. Vertical knife is provided with an arc radius of $0.085 \mathrm{~m}$ and it delays the lemon fruit travel from the stopper to the vertical cutting edge. Vertical knife is the first to give incision and as the incision progresses vertically, the wing shaped knife imparts incision horizontally at a radius of $0.1 \mathrm{~m}$, ensuring four pieces of similar size and shape at the end of each sweep.

Table 3 Specifications of lemon cutting machine

\begin{tabular}{ll}
\hline Description & Value \\
\hline Throughput & $3600 \sim 5040 \mathrm{Nos} / \mathrm{h}$ \\
Speed of centralizing disc & $10 \sim 14 \mathrm{RPM}$ \\
Diameter of side plates & $0.25 \mathrm{~m}$ \\
Diameter of groove & $0.2 \mathrm{~m}$ \\
Overall size of the machine & $0.40 \mathrm{~m} \times 0.44 \mathrm{~m} \times 0.80 \mathrm{~m}$ \\
& $(\mathrm{Length} \times$ Width $\times$ Height $)$ \\
Power required & $0.11 \mathrm{~kW}$ \\
Weight of machine & $\sim 50 \mathrm{~kg}$ \\
Attendants required to operate & $1 \mathrm{No}$. \\
\hline
\end{tabular}

Power consumption

Shear force required for slicing the lemon was measured in two directions, namely, along and across the direction of segment (as the direction of fruit segments will be different). The results are shown in Table 1. It can be clearly seen that the shear force required for making the incision on the lemon in both these directions is different. Shear force required for incision across the axis of the fruit segments was less compared to that in the other direction. Accordingly, the shear stress value when cut across the segment was less than that in the other direction.

It may be noted that the shear force for cutting the lemon is in the range of $322 \sim 433 \mathrm{~N}$ and the corresponding shear stress to be in the range of $201 \times 10^{3} \sim 314 \times 10^{3} \mathrm{~N} / \mathrm{m}^{2}$. The maximum torque required for cutting the lemon continuously at the maximum rated speed of 14 RPM is found to be $7.5 \mathrm{~kg}-\mathrm{m}$ and the theoretical power of the electric motor to be around $0.11 \mathrm{~kW}$. However, a geared electric motor of higher power rating of $0.75 \mathrm{~kW}$ has been selected considering transmission/operational loss in the gear box besides the availability in the market.

\section{Rated capacity}

The prototype continuous lemon cutting machine can accommodate single lemon in each of the six of centralizing discs at any given time. The side plates are rotated at a speed ranging from 10 RPM to 14 RPM. The machine had a capacity to cut lemon at 3,600 5,040 lemons per hour with a variation in their diameter ranging from $0.040 \mathrm{~m}$ to $0.046 \mathrm{~m}$.

\section{Juice ejection}

Studies are carried out to estimate the oozing of juice during cutting of lemon into four pieces at different rotational speeds and the results are shown in Table 2. It can be observed from the table that the juice ejection was minimal and also that the speed of centralizing disc has very less effect on juice ejection in the range of rotational speed studied (10 14 RPM).

\section{Performance evaluation of the machine}

The geared motor of the lemon cutting machine was set to rotate at a rotational speed ranging from 10 RPM to 14 RPM. Unsorted (irrespective of fruit maturity and diameter) lemons were loaded continuously on to the feeding tray which in turn were directed into the chute. The stopper (Fig. 1) ensured its intended pickup of lemons one at a time and in turn to be centralized in the centralizing disc. Capacity of the equipment to cut the lemons into four pieces was 
evaluated using Eq. (3). The same capacity was observed during the trial run (since no spill over of lemons occurred during pick up and loading) as can be seen from the Table 2. Thus it enabled successful performance evaluation of prototype to be carried out with respect to design parameters and capacity. Further, the performance of the prototype machine (as shown in Fig. 5) was found to be good at rotational speed even below 10 RPM however, it was found to be poor at a speed above 14 RPM. The final specifications of the lemon cutting machine are given in Table 3.

\section{Conclusion}

A continuous lemon cutting machine was designed and developed for cutting lemons hygienically into four pieces. By conducting several trials, modifications are incorporated in the prototype during several iterations, to improve the operational efficiency. Performance evaluation trials were carried out over the designed rotational speed of $10 \sim$ 14 RPM and found to be satisfactory with respect to the designed capacity $(3,600 \sim 5,040$ lemons/h) with minimum juice ejection $(0.52 \sim 0.68 \mathrm{ml} /$ Lemon). The theoretical electrical power required for the lemon cutting machine is around $0.11 \mathrm{~kW}$. Unsorted lemons were fed and the machine was found to be able to handle the size variation. The concept of this machine can be applied to handle similar fruits of larger size also.

Acknowledgments The authors wish to gratefully acknowledge the support and encouragement of Director, CFTRI, Mysore. The authors thank S. Raghavendra Guru, R. Somashekar and Shaisuddin for their help during the measurement of shear force and shear stress values. The authors also wish to thank S.G. Jayaprakashan, G. Bammigatti, I. Mahesh and BV. Puttaraju for their help during experimentation.

\section{Appendix}

Calculation of arc radius $(\mathrm{R})$ of the vertical knife

\section{Linear velocity for Conventional cutting:}

Linear distance (minimum) to which the knife moved during manual cutting of lemon was observed to $b e=0.25 \mathrm{~m}$

Time (minimum) required to cut the lemon (diameter $0.04)$ manually $=5 \mathrm{~s}$

Linear velocity (minimum) required to cut the lemon manually $=$ Distance travelled/time $=0.04 \mathrm{~ms}^{-1}$

Linear velocity, (minimum) required to cut the lemon manually, is $0.04 \mathrm{~ms}^{-1}$ for the distance of $0.25 \mathrm{~m}$ and time $5 \mathrm{~s}$.
Equating the linear distance travelled by the knife to cut the lemon to the arc radius (R) of the vertical knife

$2 \pi R=0.25$

Or

$\mathrm{R}=0.04 \mathrm{~m}$

Thus the theoretical value of radius $(\mathrm{R})$ is $0.040 \mathrm{~m}$. However, in order to provide sufficient time for the lemon to get centralized in the centralizing disc, an arc radius (R) of $0.085 \mathrm{~m}$ has been chosen.

Angular velocity ( $\omega)$ for cutting in machine:

Arc radius of vertical knife $(\mathrm{R})=0.085 \mathrm{~m}$

Circumference $=2 \pi \mathrm{R}=2 \pi \times 0.085=0.54 \mathrm{~m}$

Rated speed $(\mathrm{N})=10 \sim 14 \mathrm{RPM}$

Angular velocity $(\omega)$ at $10 \mathrm{RPM}=(10 \times 0.54) / 60=$ $0.09 \mathrm{~ms}^{-1}$

Angular velocity $(\omega)$ at $14 \mathrm{RPM}=(14 \times 0.54) / 60=$ $0.13 \mathrm{~ms}^{-1}$

Angular velocity $(\omega)$ required to cut the lemon varied in the range of $0.09 \sim 0.13 \mathrm{~ms}^{-1}$ for the rated rotational speed of 10 14 RPM.

It can be noted that the angular velocity $(\omega)$ to be higher than the linear velocity (minimum) of conventional cutting (indicated above) and hence ensuring successful cutting of lemons continuously in the present design of the lemon cutting machine.

\section{References}

Anonymous (1947) Manufacture of Indian pickles, chutneys and morabbas, supplied by the manufacture of jams, jellies, marmalades etc. Industry Publishers Ltd, India

Bilim HIC, Polat R (2008) Splitting and breaking of pistachio nuts with striking and heating. J Food Process Eng 31:317-329

Binsted RH (1939) Pickle and sauce making. Food Trade Press, London Bose TK (1991) Fruits of India-tropical and sub-tropical. Naya Prakash, India

Bose TK, Mitra SK (1990) Fruits-tropical and sub-tropical. Naya Prakash, India

Breverman JBS (1949) Citrus products-chemical composition and chemical technology. Interscience publishers, Inc, New York

Brown M (1955) Pickles and preserves. Wilfred Funk, Inc, New York

Cheema GS, Bhat SJ, Naik KC (1954) Commercial fruits of India. Macmillan \& co, India

Chicoine L, Joncas JH (1973) Use of lactic enzymes in non bacterial gastroenteritis. Union Med Can 102:1114-1115

Ghanbarian D, Kolchin NN, Beigi SRH, Ebrahimi R (2010) Design and development of a small potato-grading machine using capron net. J Food Process Eng 33:1148-1158

Jarimopas B, Pechsamai A (2002) Design and development of young coconut peeling machine. Thail Agric Res J 20(2):91-110

Jarimopas B, Pramote K (2007) A young coconut fruit opening machine. Biosyst Eng 98:185-191

Jarimopas B, Ruttanadat N (2006) Development of a young coconut fruit trimming machine. J Food Eng 79:752-757 
Jarimopas B, Kitawee A, Rangsri W, Toomsaengtong S (2002) Automatic leaf area measurement system. Thail Soc Agric Eng J 9(1):57-63

Jarimopas B, Niamhom S, Terdwongworakul A (2009a) Development and testing of a husking machine for dry betel nut (Areca Catechu Linn.). Biosyst Eng 102:83-89

Jarimopas B, Ruttanadat N, Terdwongworakul A (2009b) An automatic trimming machine for young coconut fruit. Biosyst Eng 103:167-175

Milind SL (2008) Citrus fruit-biology, technology and evaluation. Academic, New York

Pandey A, Singh GP, Raja RB (2011) A novel method to produce low salinity and healthier Indian lemon (Citrus limonum) pickle. Ann Biol Res 2(1):187-194

Renther W, Webber HJ, Batchelor LD (1967) The citrus industry, Vol-1, history, world distribution and varieties. Centennial Publication of University of California, California
Sanni LL, Ogunsina BS, Oladigbo C (2008) Development of rotary pulverizer for cassava cake in Gari production. J Food Process Eng 31:783-797

Venkateshmurthy K, Jayaprakashan SG, Shivakumar M (2002) A machine useful for cutting fruits and vegetables. Patent No; IN226043

Venkateshmurthy K, Jayaprakashan SG, Ezhil Murugan A (2003) Continuous vibro fluid bed roaster for roasting of cereals, pulses, spices, oil seeds and ready to eat snack foods. Patent No; US Patent 6810794

Venkateshmurthy K, Ravi R, Bhat KK, Raghavarao KSMS (2008) Studies on roasting of wheat using fluidized bed roaster. J Food Eng 89:336-342

Wolfgang Delfs-Fritz (1970) Citrus, Cultivation and fertilization. RuhrStickstoff. AG. Bochum, West Germany 